Helgoländer wiss. Meeresunters. 20, 697-706 (1970)

\title{
Osmoregulation in decapod larvae as a consideration in culture techniques
}

\author{
F. A. KALBer \\ Aquatic Sciences, Inc.; Boca Raton, Florida, USA
}

KURZFASSUNG: Osmoregulation bei Decapoden-Larven und ihre Bedeutung für die Kulturtechnik. Die Larven der Decapoden weisen Veränderungen der osmoregulatorischen Fähigkeiten auf, die oft kurzfristiger Art sind und sich zwischen den Häutungsstadien manifestieren. Kurzzeitige Veränderungen der osmoregulatorischen Kapazität können von einem Tage zum anderen zutage treten. Hierfür werden Beispiele anhand von Untersuchungen an den Larven von Callinectes sapidus, Libinia emarginata und Hepatus epbeliticus gegeben. Es wird darauf hingewiesen, daß es in vielen Fällen notwendig ist, Kenntnisse über die physiologischen Vorgänge der Osmoregulation zu gewinnen, um diese für die Zucht von Decapoden-Larven nutzen zu können.

\section{INTRODUCTION}

The significance of control and manipulation of salinity in the rearing of crustacean larvae has been demonstrated through salinity tolerance experiments in several laboratories. The reports of Costiow \& Bookhout (1962), BookhouT (1964), and Costuow et al. (1966), are examples of such studies.

This kind of knowledge about changes in salinity tolerance of larvae during their development is, in itself, valuable information for culture technology. However, information about its underlying physiology can permit more effective and sensitive use of salinity change as a useful tool in the improvement of rearing techniques in many species.

During the course of experimentation on the osmotic regulation of a number of species of decapod crustaceans during their larval development, several facts about the physiology of their osmoregulation emerged which have importance for culture techniques in this group of animals. I will review these discoveries and relate them to the ways in which we have used them to advantage in culture operations at Aquatic Sciences, Inc., Boca Raton.

\section{RESULTS}

Experiments which we have carried out on osmoregulation during development in decapods has been concentrated on the following species: Callinectes sapidus, the "blue crab" of North American commerce; Rbithropanopeus barrisii, a mud crab that Euro- 

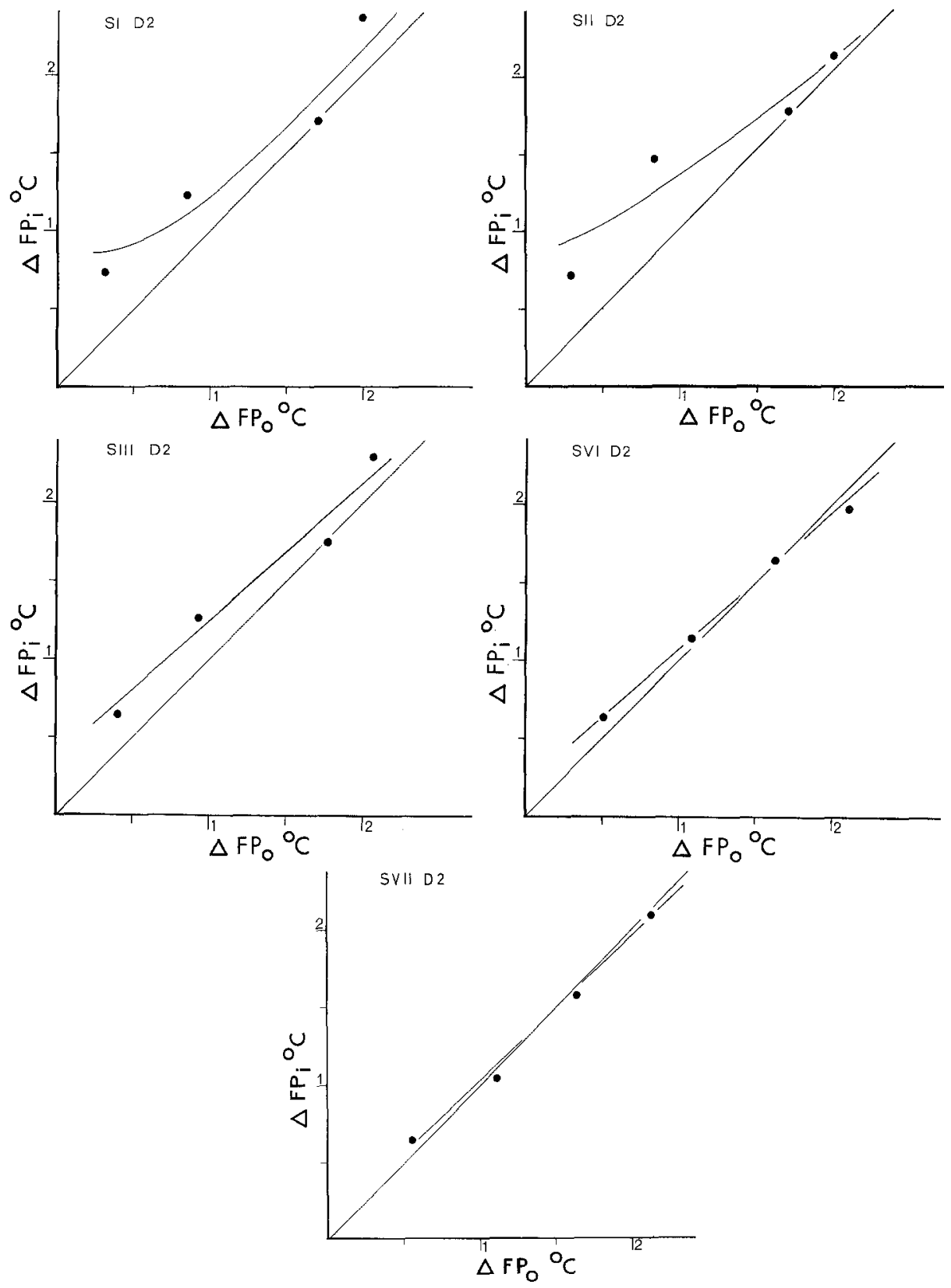

Fig. 1: Osmoregulation of zoea larvae of Callinectes sapidus. Stage I day 2 (SI D2), stage II day 2 (SII D2), stage III day 2 (SIII D2), stage VI day 2 (SVI D2), stage VII day 2 (SVII D2) 
pean biologists know well; Sesarma cinereum and $S$. reticulatum, two species of a world-wide genus of shore crabs; Hepatus epheliticus, the deep-water "calico" crab of the Eastern North American coast; and Libinia emarginata, a stenohaline spider crab. For the sake of brevity, I will present only a few of the data that we have collected about osmoregulatory changes during development in some of these species.

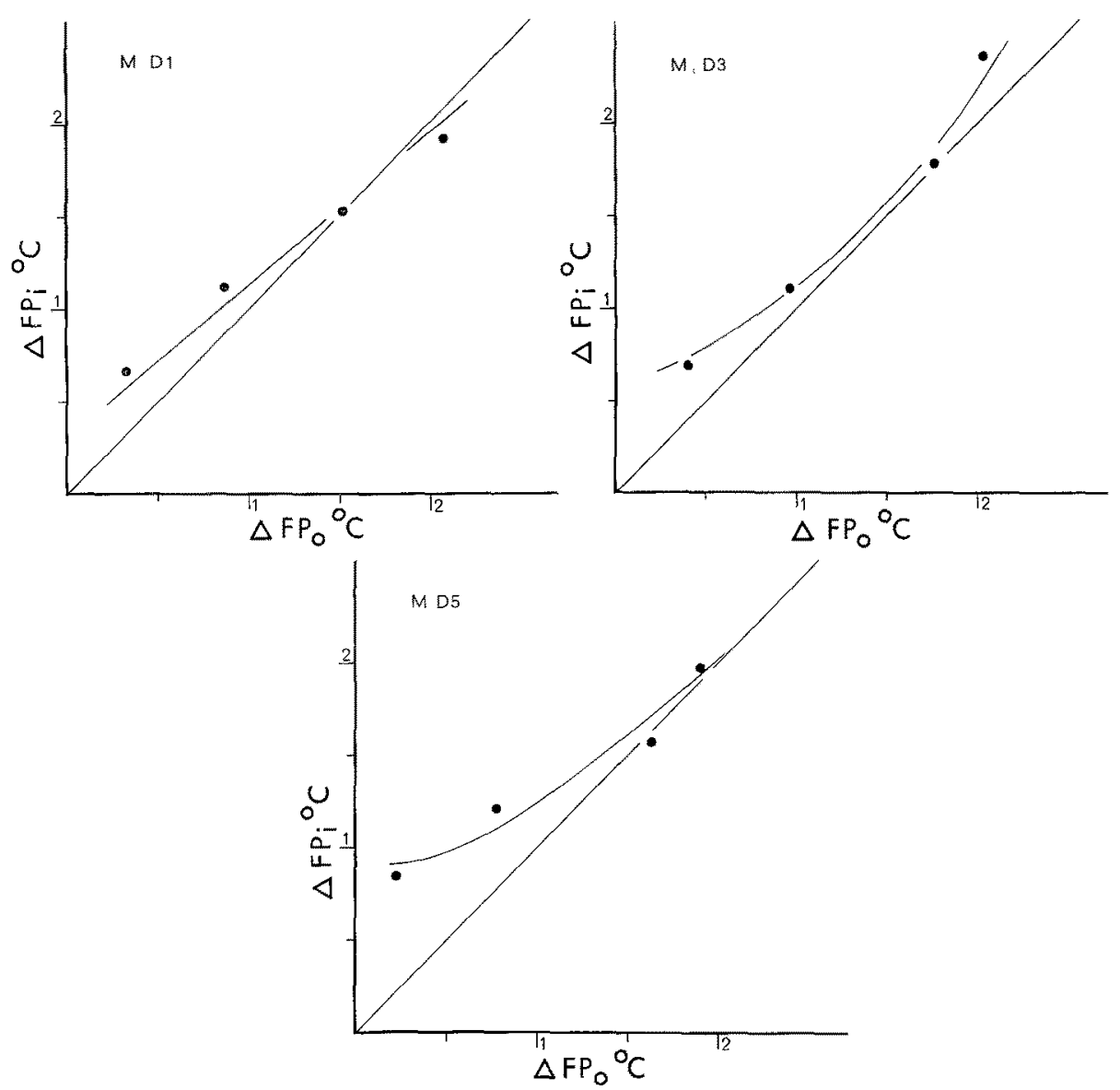

Fig. 2: Osmoregulation of megalopa larvae of Callinectes sapidus. Day 1 (M D1), day 3 (M D3), day 5 (M D5)

The analyses of internal osmoconcentration were carried out on the haemolymph of single larvae in experimental groups. This was accomplished by measuring freezing point depression of 40-80 nannolitre samples of fluid with a thermoelectric microscope stage cyroscope. All of the plots of osmoregulation present these data by opposing the freezing point depression of the haemolymph on the ordinate to that of the medium used, to challenge them on the abscissa. A diagonal of isoosmotic concen- 

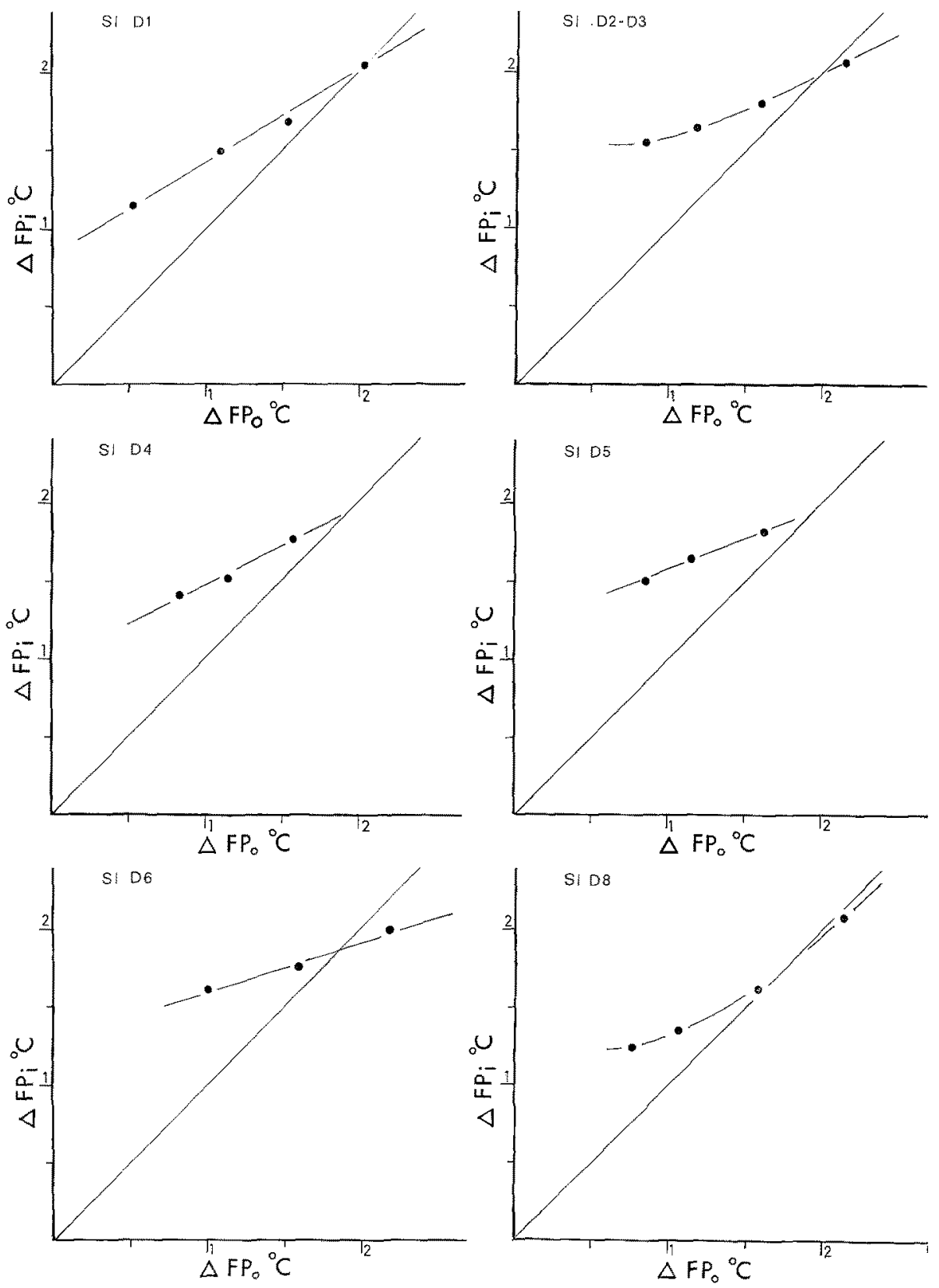

Fig. 3: Osmoregulation of zoea larvae of Hepatus epheliticus. Stage I day 1 (SI D1), stage I day 2 and 3 (SI D2-D3), stage I day 4 (SI D4), stage I day 5 (SI D5), stage I day 6 (SI D6), stage $I$ day 8 (SI D 8 ) 

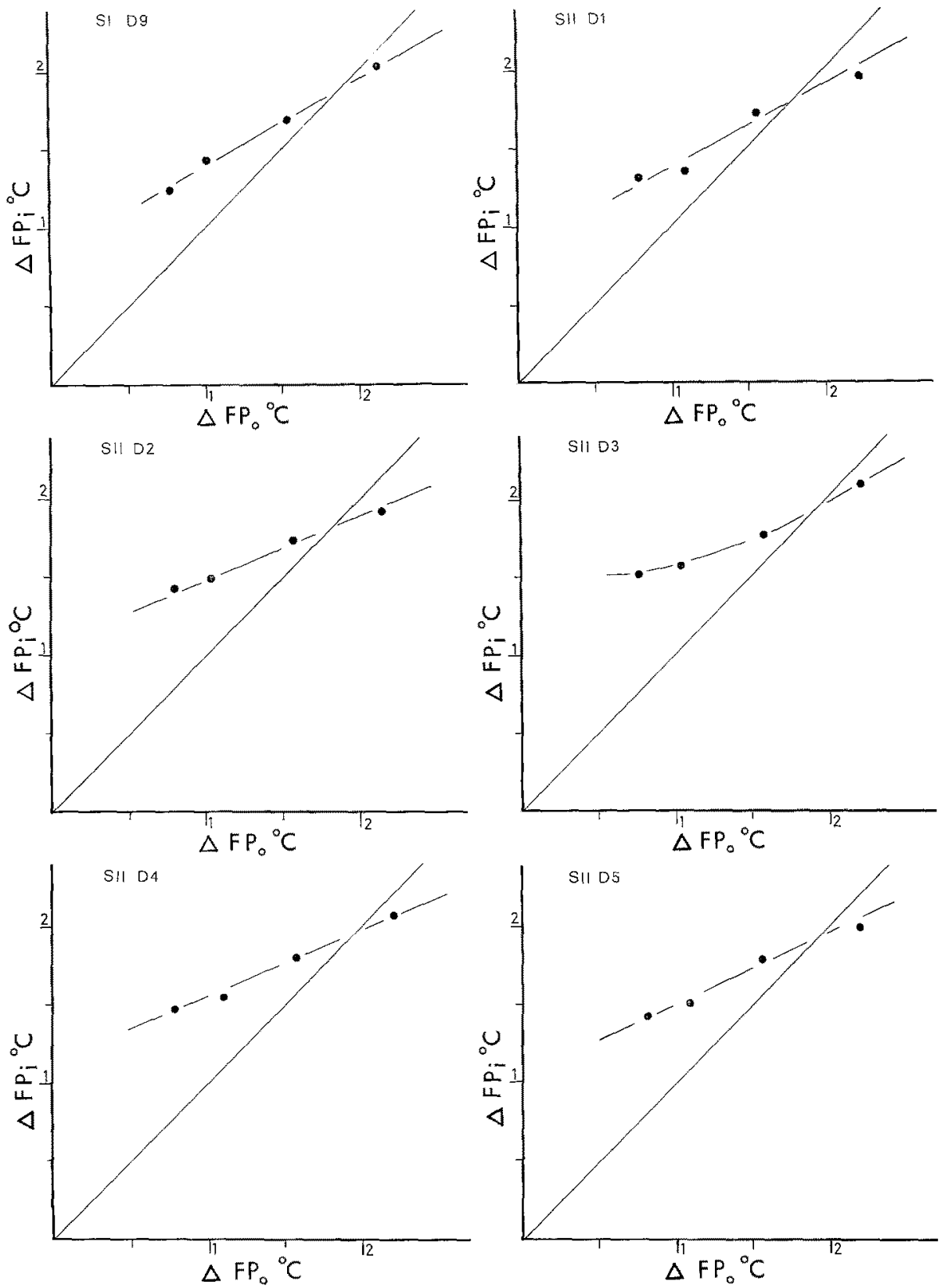

Fig. 4: Osmoregulation of zoea larvae of Hepatus epbeliticus. Stage I day 9 (SI D9), stage II day 1 (SII D1), stage II day 2 (SII D2), stage II day 3 (SII D3), stage II day 4 (SII D4), stage II day 5 (SII D5) 
tration has been drawn in all plots for reference. The larvae investigated were acclimatized to test salinities for two hours at $23-26^{\circ} \mathrm{C}$.

Figures 1 and 2 show the changes in osmoregulatory capacity of Callinectes sapidus at selected points in larval development. In this and successive plots, $S$ and D number refer to the zoeal stage and day of life in that stage. The "M" designation refers to the megalopa stage, and " $D$ " designates the day after transformation to that stage.

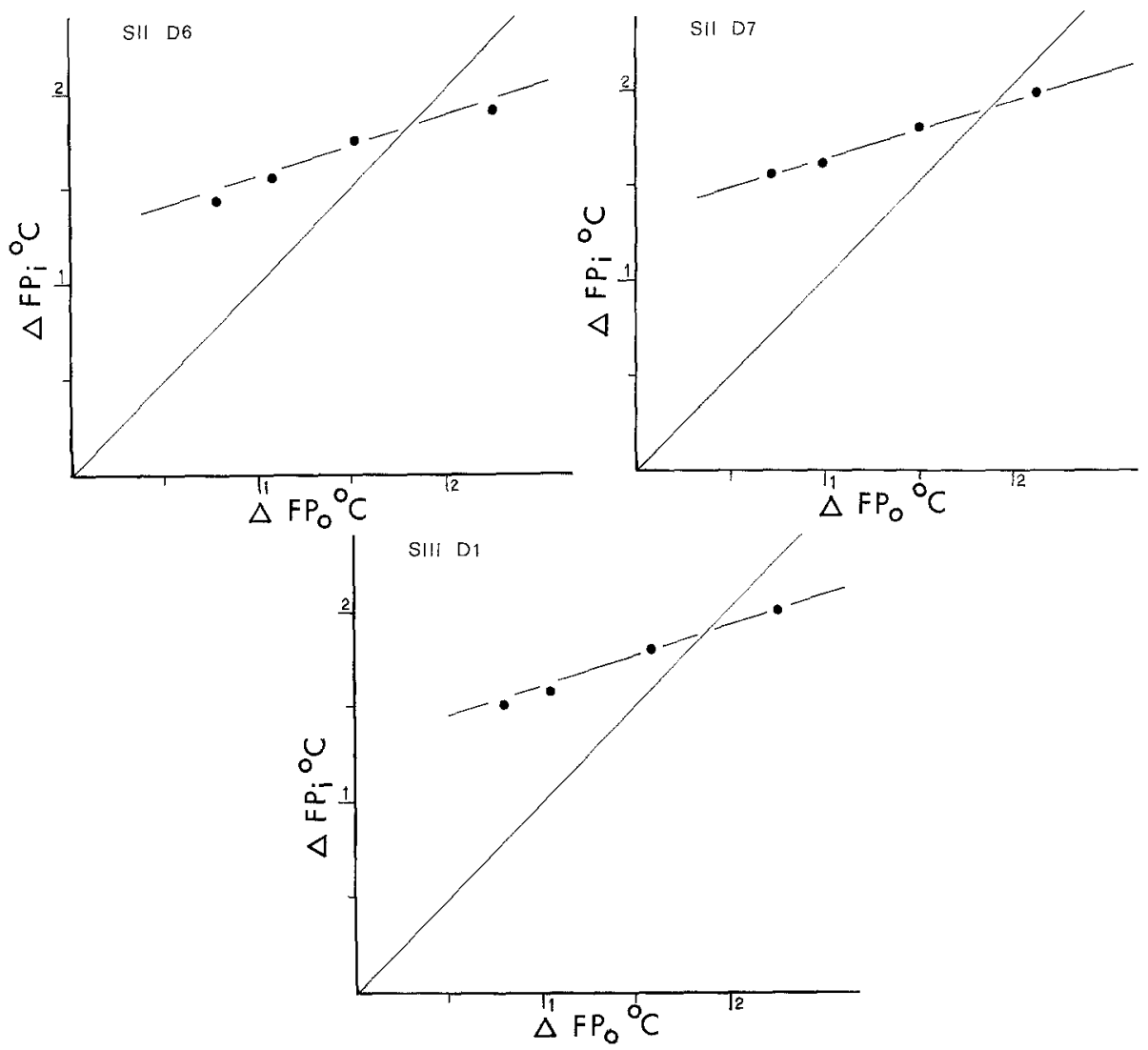

Fig. 5: Osmoregulation of zoea larvae of Hepatus epheliticus. Stage II day 6 (SII D6), stage II day 7 (SII D7), stage III day 1 (SIII D1)

It is not surprising that the larvae of a euryhaline crab such as Callinectes sapidus start life as good osmoregulators (SID2). The most surprising and useful fact in these data, however, is that the larvae lose the ability to regulate during at least one period of their life as seen in the second day of the seventh zoeal stage. It would seem that salinity control at this point in life must be more carefully maintained. There is an important question to be raised on this point which I will mention later.

Figures 3 to 5 show daily plots of osmoregulation in larvae of the calico crab, Hepatus epheliticus. As mentioned earlier, the adult is stenohaline and is found in 

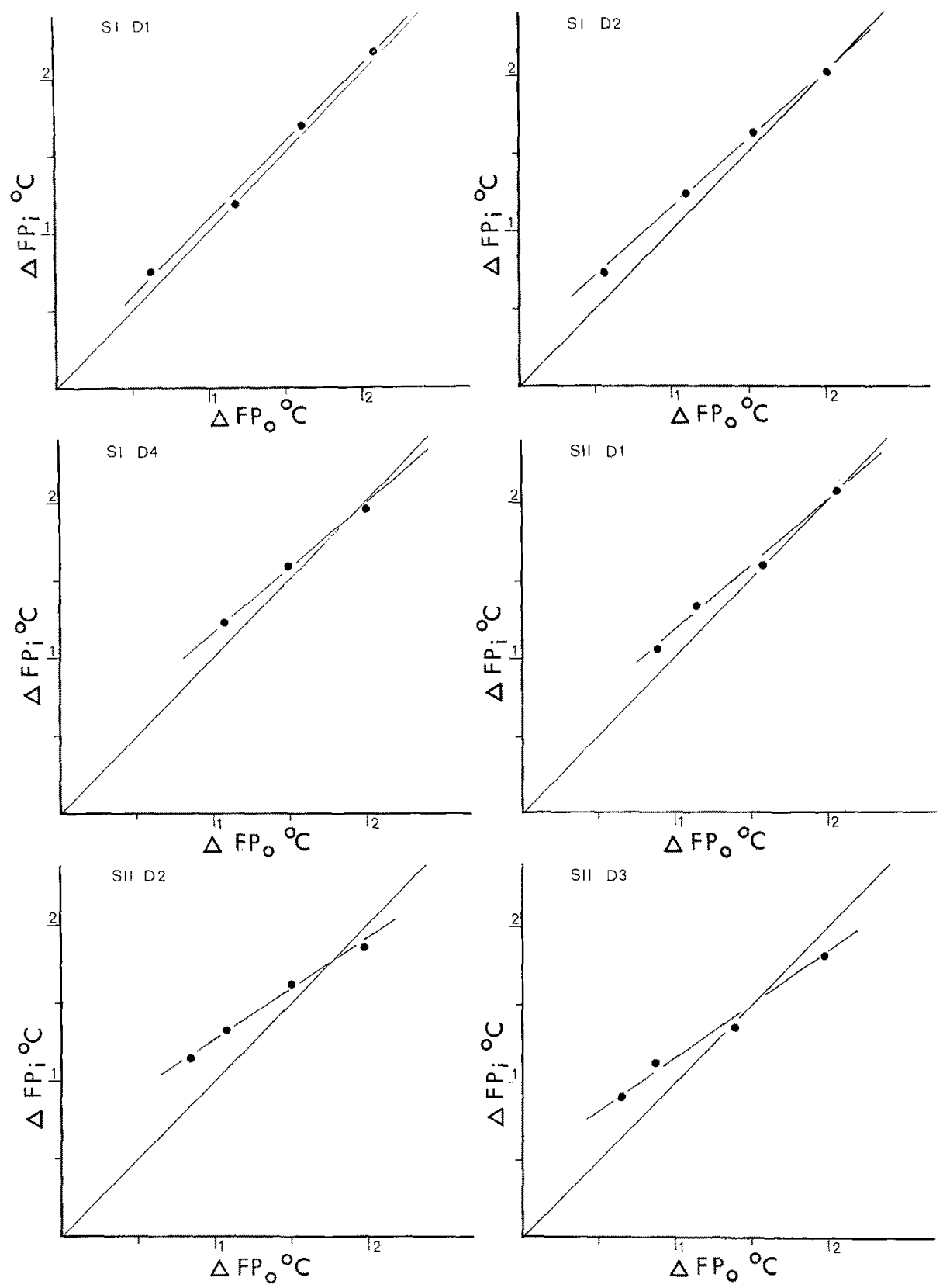

Fig. 6: Osmoregulation of zoea larvae of Libinia emarginata. Stage I day 1 (SI D1), stage I day 2 (SI D2), stage I day 4 (SI D4), stage II day 1 (SII D1), stage II day 2 (SII D2), stage II day 3 (SII D3) 

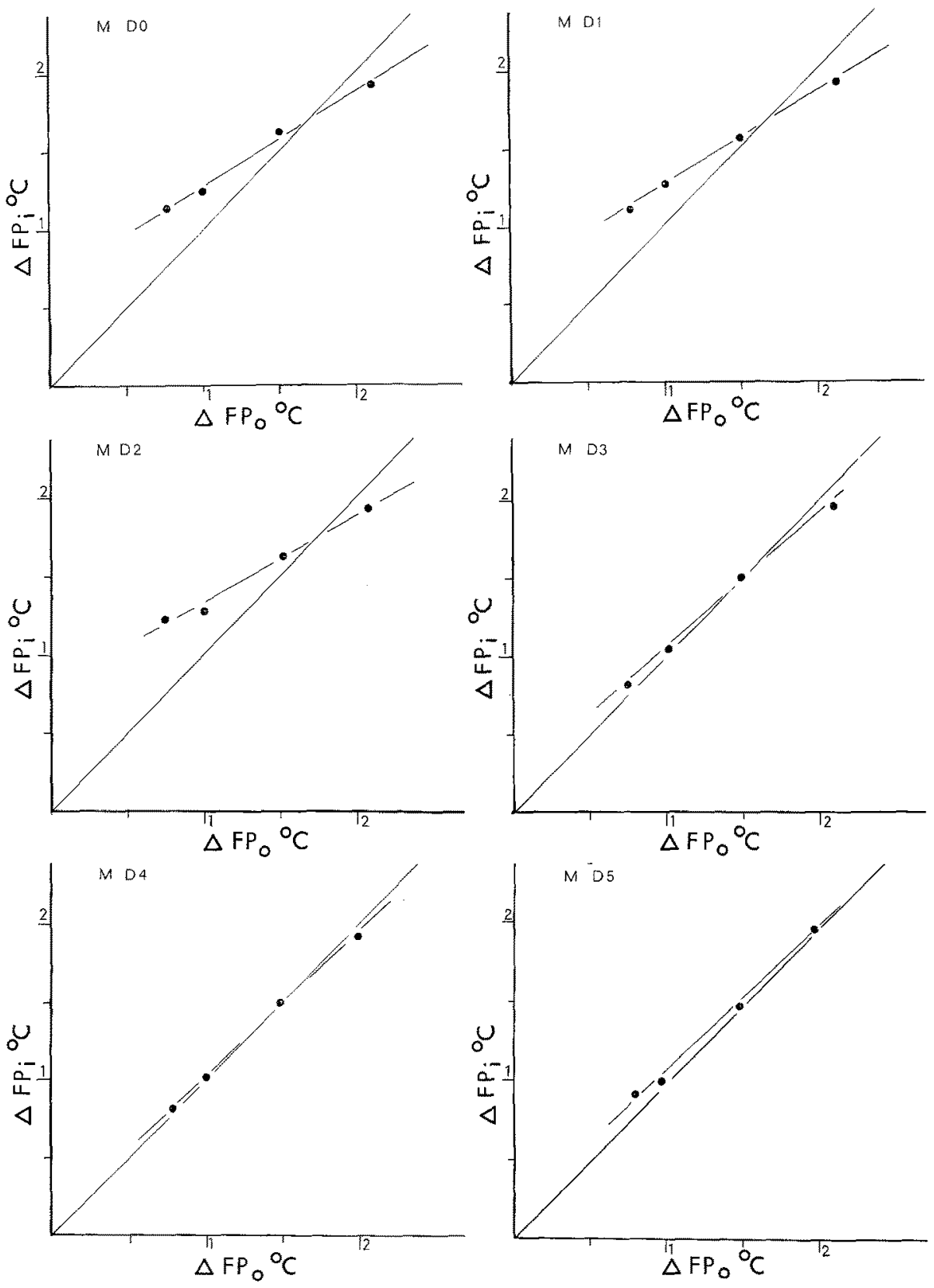

Fig. 7: Osmoregulation of megalopa larvae of Libinia emarginata. Day $O$ (M DO), day 1 (M D1), day 2 (M D2), day 3 (M D3), day 4 (M D4), day 5 (M D5) 
relatively deep littoral situations, and it was surprising to find its larvae so capable of osmoregulation from the very first day of larval life. The plots are quite uniform in this respect and the data shown here record osmoregulation to the first day of the third zoeal stage. This excellent capacity for osmoregulation is gradually lost as the larvae approach megalopa and settling crab stages. At first consideration, it would seem that we are presented with a very hardy larvae which is relatively refractory to changes in salinity during culture operations.

Figures 6 and 7 give osmoregulation plots for Libinia emarginata, a spider crab which is nearly lacking in osmoregulatory ability as an adult. Note that the capacity to osmoregulate in their larvae is gradually acquired throughout zoeal development; so that the larvae are good osmoregulators by the first day of metamorphosis into megalopa, and that this ability is slowly lost as they transform into later megalopa stages and approach the adult osmoregulatory pattern. These data present a case for critical control of culture salinity at the beginning and end of larval life and infer that the culturist can take a relatively relaxed attitude about maintenance of salinity during the middle of this species' larval history.

\section{DISCUSSION}

I have shown three distinctly different patterns of transition of osmoregulatory capacity during development in as many species of decapods. These data, together with others that we have accumulated, support the idea that osmoregulation changes during larval development are unique to each species and must be carefully investigated in each case when culture techniques are to be perfected. We have found considerable differences in osmoregulation ability even between species in the same genus. An example of this is our work on Sesarma cinereum and Sesarma reticulatum.

I have a further, and final, observation about the apparent loss and temporary acquisition of osmoregulation during development in the species discussed and in other decapods. We have discovered that osmoregulation is intimately related to the mechanics of the moult process in larval decapods as it is in adults. For example, there are many instances recorded in our files and in our publications which show what would seem to be peculiar tendencies of larvae to. hyperregulate against all osmoconcentrations presented to them; particularly good osmoregulators such as the larvae of Rhithropanopeus harrisii. This tendency becomes less puzzling in interpretation when one takes into account the physiological fact that the only manner in which larval decapods (or indeed, adults) can increase their body volume immediately after the event of moulting is by encouraging an influx of water. The physiological response of intense hyperregulation in these larvae is, therefore, a mechanism to provide the osmotic gradient required to accomplish this invasion of water, and hence allow the animals to grow in size at each metamorphic change. We know this hyperregulatory process is controlled by central nervous system hormones and we know something about the environmental conditions that set the controls into function in the larvae of some species. It is important, for instance, that larvae be given a specified osmoconcentration in their environment during some periods prior to the moult process in order that these controls can operate. 
Information about larval ability to osmoregulate is used to designate what these external conditions should be and when they should be applied. If applications of these changes in culture conditions are properly scheduled, one can expect improved rates of development and greater yields during, and at the end of, the rearing procedure.

\section{SUMMARY}

1. Larvae of decapod crustaceans, especially crabs, change their capacity to osmoregulate from day to day and between moult stages.

2. These changes are related to alterations in internal osmoconcentration so that inward flow of water increases body turgor to assist in the moulting process.

3. It is useful, therefore, and often essential, to be aware of these physiological events during the course of culture.

Acknowledgement. Nearly all of the information presented here has been acquired in collaboration with Dr. J. CostLow, Director of the Duke University Marine Laboratory at Beaufort, North Carolina, U.S.A. Much of this research was supported under the auspices of the Office of Naval Research, grant No. NR 104-194. Dr. CostLow and I collaborated for several years on this project with the assistance of his fine culture facilities and staff. We have published together on the subject of changes in osmoregulatory capacities and their control during the development of a number of decapod species. I extend his invitation and mine to any one who would like to request copies of these publications and who would like to visit his culture laboratory at Duke University or mine at Aquatic Sciences, Inc. in Boca Raton, Florida, U.S.A.

\section{LITERATURE CITED}

Bоокночт, C. G., 1964. Salinity effects on the larval development of Pagurus bernbardus (L.) reared in the laboratory. Ophelia 1, 275-294.

Costlow, J. D. \& Bookhout, C. G., 1962. The effect of environmental factors on larval development of crabs. In: Biological problems in water pollution. 3rd Seminar, 1962. Planned and assembled by C. M. Tarzwell. US Dpt of Health, Education, and Welfare, Public Health Serv., Div. of Wat. Supply and Poll. Control, Cincinnati, Ohio, 77-86. (Publ. Hlth Serv. Publ. 999-WP-25.)

- - \& Monroe, R. J., 1966. Studies on the larval development of the crab, Rbithropanopeus harrisii (GoulD). 1. The effect of salinity and temperature on larval development. Physiol. Zool. 39, 81-100.

Author's address: Dr. F. A. Kalber

Aquatic Sciences, Inc.

2624 N.W. Second Avenue

Boca Raton, Florida, USA 